\section{Galactomannan and Isolichenan Components of the Carbohydrate- rich Lichen Ramalina ecklonii (Spreng.) Mey. \& Flot.}

\author{
Adirce Moreira MICENO, \\ Philip Albert James GorIN \\ and Marcello IACOMINI \\ Departamento de Bioquimica da Universidade, \\ Federal do Paraná, P.O. Box 19046, \\ 81.531-Curitiba-PR., Brazil
}

Received July 3, 1990

The lichen Ramalina ecklonii, which is abundant in the State of Paraná, Brazil, was collected close to the city of Curitiba in sunny locales at the edge of lakes and thickets. It was extracted with benzene-ethanol and then with aqueous methanol to provide mainly arabinitol and mannitol (15\% yield) in a $7.3: 1$ molar ratio (by GC of the derived acetates). Hot aqueous extraction of the residual lichen liberated a polysaccharide ( $38 \%$ yield), which contained $83 \%$ of glucose. The polysaccharide in water was frozen, thawed and the insoluble material removed. The supernatant was treated with Fehling solution to give an insoluble copper complex (regenerated galactomannan $\mathrm{A}, 2.2 \%$ yield), leaving in the supernatant isolichenan (26\% yield). It was similar to that of Ramalina usnea, ${ }^{1)}$ with $\alpha-(1 \rightarrow 3)$ and $\alpha-(1 \rightarrow 4)$ linkages in a ratio of $3: 1$. Its yield was much higher than the previous figure reported for an isolichenan, which was $9 \%$ from Alectoria sulcata. ${ }^{2)}$

The residual lichen was further extracted with hot aqueous potassium hydroxide to liberate a further $6 \%$ of polysaccharide. This was treated with Fehling solution to provide an insoluble $\mathrm{Cu}$ complex from which galactomannan $\mathrm{B}$ (3.8\% yield) was regenerated.

Galactomannans A and B were treated with Cetavlon, and the precipitates were regenerated, respectively, to give galactomannans $\mathrm{C}$ and $\mathrm{D}$. The former (1.9\% yield) had $2.7 \%$ protein; ratio of galactose to mannose, $46: 54 ;[\alpha]_{D}^{25}$ $+60^{\circ}$ in water. The values for galactomannan D $(3.5 \%$ yield) were $3.9 \%, 43: 57$ and $+57^{\circ}$, respectively. They were homogeneous in a column of Sephadex 4B-200 $(50 \times$ $2.1 \mathrm{~cm}$ ) eluted with water. Their ${ }^{13} \mathrm{C}-\mathrm{NMR}$ spectra each contained C-1 signals at $\delta 104.7(\beta$-D-Galp- $(1 \rightarrow 4)-\alpha-\mathrm{D}-$ Manp) and $101.9(\alpha-D-M a n p-(1 \rightarrow 6)$ units of the main chain and others substituted at $0-4) .{ }^{1}$ In addition, galactomannan $\mathrm{C}$ gave two additional small signals at $\delta 102.8$ and 82.9 , which correspond respectively to $\mathrm{C}-1$ of $\mathrm{Gal} p$ and C-2 of Manp involved in a $\alpha-\mathrm{D}-\mathrm{Gal} p-(1 \rightarrow 2)-\alpha-\mathrm{D}$ Manp-disaccharide unit.

A methylation analysis of galactomannan $\mathrm{D}$ indicated non-reducing end units of Galp $(41 \%)$ and $\operatorname{Man} p(2 \%)$, and 6-O- $(20 \%), 4,6-\mathrm{di}-O-(24 \%)$ and 2,4,6-tri- $O$ substituted Manp residues $(8 \%)$. These data are in agreement with a Smith degradation, in which the galactomannan was converted to acetates of glycerol $(65 \%)$, erythritol $(22 \%)$, mannitol $(11 \%)$ and galactitol $(2 \%)$.

Partial acetolysis of galactomannan $\mathrm{D}$ gave disaccharides whose ${ }^{1} \mathrm{H}-\mathrm{NMR}$ spectrum showed a mixture of 2-O- $\alpha$-D-Galp- $(1 \rightarrow 2)-\alpha-\mathrm{D}-\mathrm{Man} p(\delta 5.38, J=1.0 \mathrm{~Hz}(\mathrm{H}-\mathrm{I})$ and $\left.5.08, J=3.8 \mathrm{~Hz}\left(\mathrm{H}-1^{\prime}\right)\right)^{1 /}$ and $4-O-\beta$-D-Gal $p-(1 \rightarrow 4)-\alpha \beta$ D-Manp ( $\alpha$-anomer: $\delta 5.11, J=1.7 \mathrm{~Hz}(\mathrm{H}-1)$ and 4.37 , $J=7.7 \mathrm{~Hz}\left(\mathrm{H}-1^{\prime}\right), \beta$-anomer: $\delta 4.84, J=0 \mathrm{~Hz}(\mathrm{H}-1)$ and

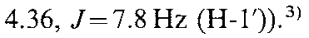

The overall evidence shows that galactomannan $D$ had a. $(I \rightarrow 6)$-linked $\alpha$-D-Man $p$ main chain which was unsubstituted $(22 \%)$, monosubstituted at $O-4$ by $\beta$-D-Gal $p$ $(44 \%)$, and disubstituted at $O-4$ with $\beta$-D-Galp and at $O-2$ with D-Galp (33\%). In summary, the galactomannan had a structure differing from those of other lichens, ${ }^{4)}$ includingthat of Ramalina usnea, which has 2 of every 3 main-chain units monosubstituted with $\beta$-D-Galp units. ${ }^{1)}$

\section{Experimental}

Isolation of the polyols of $R$. ecklonii. The lichen $(239 \mathrm{~g})$ was extracted with refluxing $9: 1(\mathrm{v} / \mathrm{v})$ benzene-ethanol (1.21), and then by methanol containing $20 \%$ of water (1.21). The latter was evaporated, de-ionized and evaporated to give mixed polyols $(35.5 \mathrm{~g})$.

Hot aqueous extraction of the lichen. The lichen residue $(203 \mathrm{~g})$ was extracted with water $(1.21)$ at $100^{\circ} \mathrm{C}$ for $8 \mathrm{hr}$. The filtrate was concentrated to $200 \mathrm{ml}$, added to excess ethanol, and the precipitate isolated in a $91.4 \mathrm{~g}$ yield. Its solution in water $(300 \mathrm{ml})$ was frozen and then gradually thawed, and the resulting precipitate centrifuged off. The material soluble in water (1.41) was treated with Fehling solution (2.81), and the precipitated $\mathrm{Cu}$ complex was converted to galactomannan $\mathrm{A}$ in a $5.2 \mathrm{~g}$ yield. This was dissolved in water $(250 \mathrm{ml})$ and fractionally precipitated with $5 \%$ Cetavlon in water $(250 \mathrm{ml})$. The resulting precipitate was centrifuged off, and the supernatant treated with $3 \%$ aqueous borax $(500 \mathrm{ml}, \mathrm{pH} 8.5$ finally) giving a precipitate which was isolated and decomposed with acetic acid. The addition of excess ethanol precipitated galactomannan $C$ in a yield of $4.3 \mathrm{~g}$.

The supernatant from the Fehling precipitation was made neutral with HOAc, de-ionized evaporated to a small volume, and the dissolved isolichenan precipitated with excess ethanol in a yield of $62.9 \mathrm{~g},[\alpha]_{\mathrm{D}}^{25}+213^{\circ}(c 0.6$, $\mathrm{H}_{2} \mathrm{O}$ ). 
Aqueous alkaline extraction of the remaining lichen. The remaining lichen $(110 \mathrm{~g})$ was treated with $2 \%$ aqueous $\mathrm{KOH}(1.2 \mathrm{l})$ at $100^{\circ} \mathrm{C}$ for $1 \mathrm{hr}$, the solution neutralized (HOAc), and the polysaccharide isolated via ethanol precipitation in a yield of $14.4 \mathrm{~g}$. This was submitted to Fehling precipitation ( $\rightarrow$ galactomannan B, $9.1 \mathrm{~g}$ ) and Cetavlon procedures $(\rightarrow$ galactomannan $\mathrm{D}, 8.3 \mathrm{~g}$ ) already described.

$G C$ of the alditol acetates. The alditol acetate mixtures, which were obtained from the methanol extract after an acid hydrolysis of the polysaccharide $\left(2 \mathrm{~N}\right.$ TFA, $100^{\circ} \mathrm{C}$, $5 \mathrm{hr}$ ) and a Smith degradation, ${ }^{3)}$ were examined in a conventional GC column of OV-225 at $190^{\circ} \mathrm{C}$.

Partial acetolysis of galactomannan D. Galactomannan $\mathrm{D}(150 \mathrm{mg})$ was treated with $\mathrm{Ac}_{2} \mathrm{O}-\mathrm{HOAc}-\mathrm{H}_{2} \mathrm{SO}_{4}$ for 4 days, ${ }^{5}$ the product de- $O$-acetylated, and the resulting mixture fractionated on Whatman no. 3 paper $(2: 1: 1(\mathrm{v} / \mathrm{v})$ solvent of $n$ - $\left.\mathrm{BuOH}-\mathrm{EtOH}-\mathrm{H}_{2} \mathrm{O}\right)$, giving a disaccharide micture $(19 \mathrm{mg})$.

Methylation analysis of galactomannan $D$. Under the previously described conditions, ${ }^{3)}$ galactomannan $(5 \mathrm{mg})$ was methylated, the product hydrolyzed, and a mixture of partly $O$-methylated alditol acetates prepared. This mixture was submitted to GC-MS, using a capillary column of OV-225 installed in a Model 4000 Finnigan unit. Injection was made at $50^{\circ} \mathrm{C}$, and a rapid program of $40^{\circ} \mathrm{C} / \mathrm{min}$ to $220^{\circ} \mathrm{C}$, which was then held, was carried out.

NMR spectroscopy. Spectra were obtained with a Bruker AM-360 WB spectometer incorporating a Fourier transform system. Samples were run in $\mathrm{D}_{2} \mathrm{O}$ at $70^{\circ} \mathrm{C}$ $\left({ }^{13} \mathrm{C}-\mathrm{NMR}\right)$ and at $33^{\circ} \mathrm{C}$ under presaturation conditions $\left({ }^{1} \mathrm{H}-\mathrm{NMR}\right) . \delta$ values are based on TMS as the external standard.

\section{References}

1) P. A. J. Gorin and M. Iacomini, Carbohydr. Res., 126, 119 (1984)

2) T. Takeda, M. Funatsu, S. Shibata and F. Fukuoka, Chem. Pharm. Bull., 20, 2445 (1972).

3) M. Baron, P. A. J. Gorin and M. Iacomini, Agric. Biol. Chem., 53, 1751 (1989).

4) P. A. J. Gorin, M. Baron and M. Iacomini, "Storage Products of Lichens," in Handbook of Lichenology, Vol. III, ed. by M. Galun, CRC Press, Boca Raton, Florida, 1988, p. 9.

5) Y.C. Lee and C. E. Ballou, Biochemistry, 4, 257 (1965). 